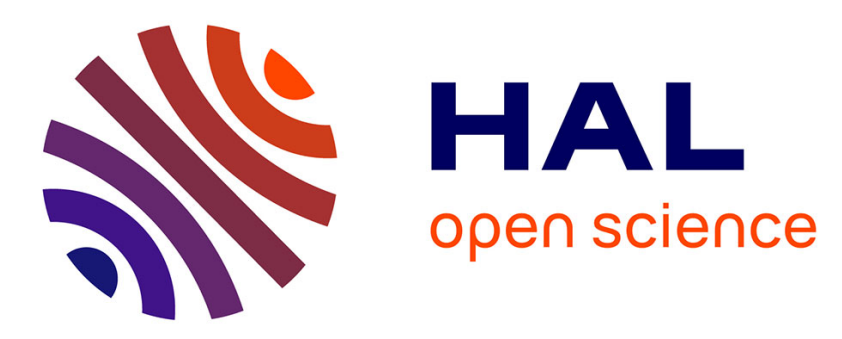

\title{
Microsatellite analysis in museum samples reveals inbreeding before the regression of Bombus veteranus
}

Kevin Maebe, Ivan Meeus, Jafar Maharramov, Patrick Grootaert, Denis Michez, Pierre Rasmont, Guy Smagghe

\section{- To cite this version:}

Kevin Maebe, Ivan Meeus, Jafar Maharramov, Patrick Grootaert, Denis Michez, et al.. Microsatellite analysis in museum samples reveals inbreeding before the regression of Bombus veteranus. Apidologie, 2013, 44 (2), pp.188-197. 10.1007/s13592-012-0170-9 . hal-01201286

\section{HAL Id: hal-01201286 \\ https://hal.science/hal-01201286}

Submitted on 17 Sep 2015

HAL is a multi-disciplinary open access archive for the deposit and dissemination of scientific research documents, whether they are published or not. The documents may come from teaching and research institutions in France or abroad, or from public or private research centers.
L'archive ouverte pluridisciplinaire HAL, est destinée au dépôt et à la diffusion de documents scientifiques de niveau recherche, publiés ou non, émanant des établissements d'enseignement et de recherche français ou étrangers, des laboratoires publics ou privés. 


\title{
Microsatellite analysis in museum samples reveals inbreeding before the regression of Bombus veteranus
}

\author{
Kevin Maebe $^{1}$, Ivan Meeus ${ }^{1}$, Jafar Maharramov ${ }^{1}$, Patrick Grootaert ${ }^{2}$, \\ Denis Michez ${ }^{3}$, Pierre Rasmont ${ }^{3}$, Guy Smagghe ${ }^{1}$ \\ ${ }^{1}$ Laboratory of Agrozoology, Department of Crop Protection, Faculty of Bioscience Engineering, Ghent University, \\ Coupure links 653, 9000 Ghent, Belgium \\ ${ }^{2}$ Royal Belgian Institute of Natural Sciences, Department Entomology, Vautierstraat 29, 1000 Brussels, Belgium \\ ${ }^{3}$ Laboratoire de Zoology, Université de Mons-Hainaut, Place du Parc 20, 7000 Mons, Belgium
}

Received 15 May 2012 - Revised 18 August 2012 - Accepted 27 September 2012

\begin{abstract}
The worldwide decline of pollinators is an emerging threat and is a matter both for ecological and economic concerns. Population genetics can be used to correlate bumblebee decline with genetic parameters. In order to do so, historical data are needed. We used eight microsatellite loci to genotype pinned museum specimens of the declining bumblebee Bombus veteranus. Bumblebee samples were collected spanning a period of three decades (1895-1923). We detected low genetic diversity and inbreeding in the samples collected during the respective time periods. Inbreeding was also confirmed by the occurrence of sterile diploid males. Based on the data obtained, we speculate that low genetic diversity and inbreeding did not directly result in the collapse of $B$. veteranus in Belgium. However, inbreeding might still play an indirect role in the decline of bumblebee populations because of the appearance of diploid males and because a low $H_{\mathrm{E}}$ might reduce the capacity to react to the drivers of bumblebee decline.
\end{abstract}

microsatellites / ancient DNA / museum collections / genetic diversity / bumblebee decline

\section{INTRODUCTION}

The decline of pollinator species is an emerging threat that is gaining attention worldwide and is a matter for both ecological and economic concerns (e.g., Klein et al. 2007; Goulson and Osborne 2010). Generalist foragers like bumblebees, which are essential pollinators in natural and managed ecosystems, are also undergoing decline (Williams 1982; Cameron et al. 2011).

Electronic supplementary material The online version of this article (doi:10.1007/s13592-012-0170-9) contains supplementary material, which is available to authorized users.

Corresponding author: G. Smagghe, guy.smagghe@ugent.be

Manuscript editor: Marina Meixner
A good example of a bumblebee species in decline in Belgium is Bombus veteranus (Thoracobombus) (Fabricius, 1793). B. veteranus lives in the plains of Northern Europe and has a highly patchy distribution as described in Rasmont and Iserbyt (2010). It was one of the most abundant bumblebees in Belgium one century ago, but it started to decline in 1950 and to date this species is almost vanished (Rasmont and Mersch 1988; Rasmont et al. 1993).

The main hypotheses to explain the observed declines in bee populations are: the impact of pathogen infections and pathogen spill-over from reared pollinators (as reviewed in Meeus et al. 2011), the use of pesticides (Thompson 2001; Blacquière et al. 2012), diet specialization (Rasmont and Mersch 1988; Connop et al. 
2010), and landscape modification (Hines and Hendrix 2005; Kremen et al. 2007).

As a consequence of this decline, bumblebee populations become increasingly small, generating new threats. One, a reduced genetic diversity may lead to a more limited evolutionary potential against future changes in the environment, such as new pathogens, climate change, and habitat loss (Frankham 2005; Zayed 2009; Goulson and Osborne 2010). Two, inbreeding (mating with relatives) can cause a decrease in polymorphism of the loci involved in the sex determination which leads to the presence of sterile diploid or triploid males (Duchateau et al. 1994; Whitehorn et al. 2009). Furthermore, inbreeding can lead to inbreeding depression caused by the expression of deleterious recessive alleles (Frankham 2005; Zayed 2009). Although, it has been reported that haplodiploid species, as is the case for bumblebees, are considered not to be as sensitive to genetic pauperization as diploid species because deleterious alleles are purged from the population in the haploid males (Sorati et al. 1996; Packer and Owen 2001). So the question remains: whether populations of haplodiploid bumblebees are under danger of extinction when severe inbreeding is detected as has been reported before for mammals (or diploid species) (i.e., Keller and Waller 2002), or can bumblebees sustain several years of inbreeding?

In this project, we used microsatellites to genotype a set of pin-mounted museum specimens of $B$. veteranus. Samples were collected spanning a period of three decades (1895-1923), before the decline occurred, and we analyzed how the allelic richness, heterozygosity and inbreeding coefficients responded over this period. These findings can increase our understanding of genetic parameters of bumblebee populations before their actual decline or extinction.

\section{MATERIAL AND METHODS}

\subsection{Museum specimens}

Belgian specimens of $B$. veteranus were selected from the Banque de Données Fauniques de Gembloux
\& Mons (Pauly and Rasmont 2010). Between 1890 and 1950, B. veteranus represents $10 \%$ of all bumblebees. This proportion decreased rapidly towards $2 \%$ between 1950 and 1970 and less than $0.5 \%$ after 1970. Rasmont et al. (1993, 2005) assessed a strong decrease of the abundance of the species by a statistical analysis of the museum collections using the Stroot and Depiereux's method (1989). The regression of the distribution is also obvious when having a look on the maps of Belgium compared to the maps of most bumblebee species (Pauly and Rasmont 2010). Multiple bumblebee workers (BV1-BV111; Electronic supplementary material (ESM), S1) present in the museum collection of The Royal Belgian Institute of Natural Sciences were chosen for three different time periods before the actual decline in 1950: $1895(n=10), 1915$ $(n=47)$, and $1923(n=32)$. For each of these time periods, a maximum distribution of this species was created (Figure 1). In addition, 10, 20, and 20 drones were selected out of each respective time period.

\subsection{DNA extraction and microsatellite protocol}

Bumblebee DNA was extracted from one middle leg of each selected museum specimen (ESM, S2). Workers were then genotyped at eight microsatellite loci that have a range lower or around $200 \mathrm{bp}$ to avoid the chance of null alleles (Wandeler et al. 2007) and that gave a reliable signal in the museum samples: B11, B126, and B132 (Estoup et al. 1993) and BT04, BT08, BT10, and BT11 (Reber Funk et al. 2006) originally developed from Bombus terrestris, and BL02 (Reber Funk et al. 2006) derived from Bombus lucorum. Microsatellites were amplified by PCR and were visualized with capillary electrophoreses (ESM, S3). To ensure data quality, some museum specimens were amplified twice at each locus; there was no evidence of amplification or scoring error based on those repeated genotyping.

\subsection{Data analysis}

Because there is a possibility of sampling multiple sisters from the same colony, which could potentially affect estimates of population genetic parameters, we 


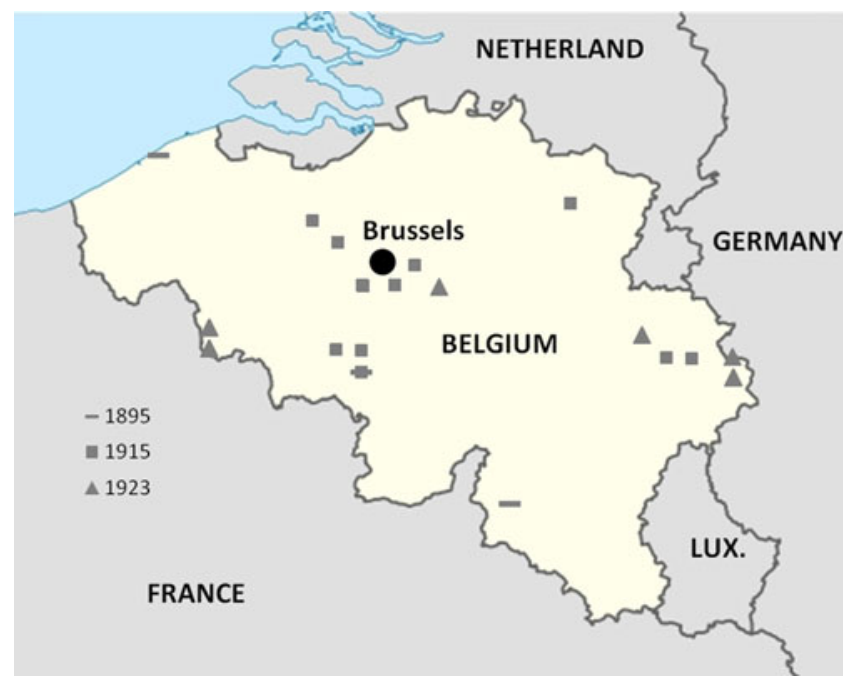

Figure 1. Distribution of the Bombus veteranus specimen collected for each year in the microsatellite analysis.

used the program Colony 1.2 (Wang 2004) to examine family relationships for each time period, employing corrections for genotyping errors (5\% per locus). We checked our data also with the program Kinalyzer (Ashley et al. 2009) with both the "2 allele" algorithm and the "consensus" method to excluded problems using Colony 1.2 on populations with low genetic variability (Ashley et al. 2008). All further analyses were made after removal of the identified sisters.

Tests for genotypic linkage disequilibrium and departures from Hardy-Weinberg (HW) equilibrium were performed for each population with randomization methods implemented in FSTAT 2.9.3 (Goudet 2001). The program GenAlEx 6.3 (Peakall and Smouse 2006) was used for testing genotype frequencies against HW equilibrium expectations. When excess homozygosity was found, the program MicroChecker 2.2.3 (van Oosterhout et al. 2004) was used to check for evidence of null alleles and their frequencies at different loci were estimated with the program FreeNA (Chapuis and Estoup 2007).

\subsection{Genetic diversity and inbreeding}

The program GenAlEx 6.3 (Peakall and Smouse 2006) was also used to calculate expected and observed heterozygosities ( $H_{\mathrm{E}}$ and $H_{\mathrm{O}}$, respectively) for each microsatellite loci. We estimated genetic diversity in each population using Nei's unbiased expected hetero- zygosity (Nei 1978) because these statistics are unbiased by sample size and do not appear to be seriously affected by null alleles (Chapuis et al. 2008). The allelic richness $\left(N_{\mathrm{A}}\right)$ corrected for sampling size $(\mathrm{El}$ Mousadik and Petit 1996) and the inbreeding coefficient $\left(F_{\text {IS }}\right)$ were estimated in FSTAT 2.9.3 (Goudet 2001). We used a paired Student's $t$ test in SPSS (version 20.0.0.1) to examine whether the mean genetic diversity and allelic richness significantly differed between different time periods. As null alleles can reach high levels when studying old museum specimens (Wandeler et al. 2007; Strange et al. 2009), the inbreeding coefficients were corrected for null allele frequencies based on the individual inbreeding model (IIM) using the program INEst (Chybicki and Burczyk 2009). The estimated distribution was used to estimate corrected allele frequencies and inbreeding coefficients using 10,000 iterations (Chybicki and Burczyk 2009).

\subsection{Population structure}

Pairwise differentiation values $\left(F_{\mathrm{ST}}\right)$ among the different time periods were calculated using 1,000 permutations in FSTAT 2.9.3 (Goudet 2001). Because null alleles may affect $F$ statistics (Chapuis and Estoup 2007) the pairwise $F_{\mathrm{ST}}$ values were recalculated after applying the ENA correction for null alleles as implemented in FREENA. We also estimated Jost's $D$ (Jost 2008). This recently developed 
statistic provides a true measure of differentiation for highly variable markers, such as microsatellites, using the software SMOGD v2.6 (Crawford 2010).

\subsection{Bottleneck presence}

Evidence of recent genetic bottlenecks in the temporal samples was tested using Garza and Williamson $(M)$ statistic (Garza and Williamson 2001). The program assumes that a reduction in population size has a stronger effect on the number of alleles $(k)$ than the range of allele sizes (rs), leading to a smaller $M$ ratio $(=k / \mathrm{rs})$ in size-reduced populations compared to equilibrium populations (Garza and Williamson 2001). In order to evaluate the likelihood of a bottleneck occurrence ( $95 \%$ criterion), the $M$ ratios calculated and averaged across loci were compared with the distribution of simulated $M_{C}$ ratios of a population in equilibrium. The $M_{C}$ ratios were simulated based on parameters describing the evolution of the analyzed microsatellite loci $(\mu$, the mutation rate/locus/generation; $\Delta_{g}$, the mean size of larger mutations; and $p_{s}$, fraction of mutations larger than a single step) and the effective population size of pre-bottlenecked populations $\left(N_{\mathrm{e}}\right)$. Each sample estimate of $M$ ratio ( $M$ critical or $M_{\mathrm{C}}$ ) was thus tested under different evolutionary scenarios as suggested by Guinand and Scribner (2003).

\subsection{Simulation of gene diversity over time}

We simulated how the genetic variation would be affected by a change in population size by use of the program BayeSSC (Excoffier et al. 2000; Anderson et al. 2005). We used the same parameters as described in Lozier and Cameron (2009) except that we let the growth factor range from 0 to $5 \%$ over 28 generations and the ancestral effective population sizes $\left(N_{\mathrm{Ae}}\right)$ from 15,000 to 100 (ESM, S4).

\section{RESULTS}

\subsection{Microsatellite data}

Of the eight microsatellite loci screened, seven (B11, B126, B132, BT04, BT10, BT11, and BL02) amplified strongly and were consistent across replicates. The locus BT08 could not be scored in a reliable manner and was therefore excluded from further analyses (Table I). Analysis with Colony 1.2, and controlled with Kinalyzer, revealed that most of the populations contained some full-sib pairs (data not shown). For populations with identified sisters, we randomly selected one individual for further analysis. Of the originally selected numbers of bumblebees: $1895(n=10), 1915(n=47)$, and $1923(n=32)$, we used in all further analyses only the numbers after removal of the identified sisters: $1895(n=6), 1915(n=34)$, and $1923(n=$ 18). Furthermore, we based all our analyses and conclusions on the time periods 1915 and 1923 as the numbers of specimens in the time period 1895 became too low. However, we still used the information obtained for the time period 1895 as indicative.

Six of the seven loci displayed heterozygote deficits under the Hardy-Weinberg equilibrium that could be indicative for inbreeding or the presence of null alleles. However, MicroChecker 2.2.3 revealed only low null allele frequencies for those loci over the different time periods $(<10 \%)$. A significant linkage disequilibrium $(P<0.05)$ was found between three pairs of loci: BL02-BT10, BL02-B11, and B11B132, when testing each locus pair across populations. The exclusion of locus BL02 and/ or B11 had no major effect on the results.

Table I. Overview of the selected microsatellite loci for the two multiplexes, their range, number of alleles and used fluorescent dyes.

\begin{tabular}{llllr}
\hline Locus & Label & Multiplex & Range & $N_{A}$ \\
\hline BT11 & 6-FAM & MP1 & $92-118$ & 14 \\
BL02 & NED & MP1 & $148-158$ & 5 \\
BT10 & VIC & MP1 & $112-140$ & 13 \\
BT08 & PET & MP1 & $160-210^{a}$ & $3^{\text {a }}$ \\
BT04 & NED & MP1 & $154-180$ & 10 \\
B11 & NED & MP2 & $124-136$ & 6 \\
B132 & VIC & MP2 & $144-158$ & 6 \\
B126 & PET & MP2 & $146-176$ & 13 \\
\hline
\end{tabular}

With label fluorescent dye, $N_{A}$ number of alleles

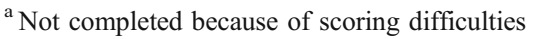




\subsection{Changes in genetic diversity}

The allelic richness $\left(N_{\mathrm{A}}\right)$ and expected heterozygosity $\left(H_{\mathrm{E}}\right)$ varied widely among loci, although differences between time periods were less pronounced (Table II). The mean $H_{\mathrm{E}}$ was $0.607 \pm 0.164($ mean $\pm \mathrm{SD})$ in 1895 , $0.577 \pm 0.310$ in 1915 , and $0.578 \pm 0.313$ in 1923 , with the difference being not significant for 1915-1923 (paired $t$ test, $t=-0.034, d . f .=6$, $P=0.98$ ). The allelic richness estimate showed a slight increase from $3.47 \pm 0.91$ in 1895 over $3.68 \pm 1.66$ in 1915 to $3.71 \pm 1.71$ in 1923 , although this difference was not significant for 1915-1923 (paired $t$ test, $t=-0.119, d . f .=6$, $P=0.91)$.

\subsection{Population structure}

Comparison of the different time periods revealed no significant genetic differentiation $\left(F_{\mathrm{ST}}\right)$ between the years (Table III). In agreement, the genetic differentiation grouped over all different time periods was also small and not significantly different from zero $\left(F_{\mathrm{ST}}=0.039\right.$, CI: $-0.008-0.090$, one sample $t$ test against 0 , $t=0.861$, d.f. $=6, P=0.42)$. Correction for the occurrence of null alleles, i.e., the ENA correction, had no effect on the genetic differentiation and was not significantly different from zero $\left(F_{\mathrm{ST}}=0.024\right.$, CI: $-0.058-0.071$, one sample $t$ test against $0, t=0.739$, d.f. $=6, P=0.48)$. Calculation of Jost $D$, another statistic to measure

Table II. After removal of identified sisters, the number of workers $(n)$, the number of alleles $(N)$, allelic richness $\left(N_{\mathrm{A}}\right)$, observed heterozygosity $\left(H_{\mathrm{O}}\right)$, expected heterozygosity $\left(H_{\mathrm{E}}\right)$, inbreeding coefficient $\left(F_{\mathrm{IS}}\right)$, and the for null alleles corrected inbreeding coefficient ( $F_{\text {IS }}$ IIM; Cybicki and Burczyk, 2009) for all microsatellite loci over the populations for each time period, with mean values and SD.

\begin{tabular}{llllllllll}
\hline Population & BT11 & BL02 & BT10 & BT04 & B11 & B132 & B126 & Mean & SD \\
\hline $1895(n=6)$ & & & & & & & & & \\
$N$ & 4.0 & 2.0 & 6.0 & 3.0 & 4.0 & 4.0 & 4.0 & 3.9 & \pm 1.2 \\
$N_{\mathrm{A}}$ & 4.00 & 1.91 & 4.89 & 3.00 & 3.58 & 3.33 & 3.58 & 3.47 & \pm 0.91 \\
$H_{\mathrm{O}}$ & 0.000 & 0.000 & 0.833 & 0.250 & 0.600 & 0.500 & 0.600 & 0.398 & \pm 0.322 \\
$H_{\mathrm{E}}$ & 0.750 & 0.278 & 0.778 & 0.656 & 0.580 & 0.625 & 0.580 & 0.607 & \pm 0.164 \\
$F_{\mathrm{IS}}$ & 1.000 & 1.000 & -0.071 & 0.619 & -0.034 & 0.200 & -0.034 & 0.383 & \pm 0.484 \\
$F_{\mathrm{IS}}$ IIM & 0.530 & 0.464 & 0.095 & 0.266 & 0.132 & 0.178 & 0.153 & $0.260^{*}$ & \pm 0.171 \\
$1915(n=34)$ & & & & & & & & & \\
$N$ & 10.0 & 3.0 & 11.0 & 7.0 & 5.0 & 4.0 & 10.0 & 7.1 & \pm 3.2 \\
$N_{\mathrm{A}}$ & 5.60 & 1.77 & 5.18 & 4.19 & 2.57 & 1.64 & 4.79 & 3.68 & \pm 1.66 \\
$H_{\mathrm{O}}$ & 0.545 & 0.000 & 0.706 & 0.421 & 0.379 & 0.042 & 0.654 & 0.392 & \pm 0.279 \\
$H_{\mathrm{E}}$ & 0.872 & 0.213 & 0.841 & 0.745 & 0.406 & 0.157 & 0.804 & 0.577 & \pm 0.301 \\
$F_{\text {IS }}$ & 0.374 & 1.000 & 0.161 & 0.435 & 0.066 & 0.765 & 0.187 & $0.423^{*}$ & \pm 0.338 \\
$F_{\text {IS }}$ IIM & 0.194 & 0.718 & 0.068 & 0.245 & 0.087 & 0.256 & 0.117 & $0.241^{*}$ & \pm 0.223 \\
$1923(n=18)$ & & & & & & & & & \\
$N$ & 9.0 & 3.0 & 7.0 & 8.0 & 5.0 & 2.0 & 7.0 & 5.9 & \pm 2.6 \\
$N_{\mathrm{A}}$ & 5.00 & 1.62 & 4.84 & 5.87 & 2.80 & 1.61 & 4.24 & 3.71 & \pm 1.71 \\
$H_{\mathrm{O}}$ & 0.231 & 0.056 & 0.529 & 0.500 & 0.529 & 0.000 & 0.692 & 0.362 & \pm 0.267 \\
$H_{\mathrm{E}}$ & 0.820 & 0.156 & 0.824 & 0.859 & 0.471 & 0.165 & 0.749 & 0.578 & \pm 0.313 \\
$F_{\text {IS }}$ & 0.718 & 0.644 & 0.357 & 0.418 & -0.125 & 1.000 & 0.075 & $0.441^{*}$ & \pm 0.386 \\
$F_{\text {IS }}$ IIM & 0.445 & 0.342 & 0.195 & 0.228 & 0.061 & 0.647 & 0.071 & $0.284^{*}$ & \pm 0.211 \\
\hline & & & & & & & & & \\
\end{tabular}

${ }^{*} P<0.05$; inbreeding coefficient significantly different from 0 
Table III. Pairwise $F_{S T}$ for the different time periods (with ENA correction) under the diagonal and the harmonic mean of $D$ est across loci above the diagonal.

\begin{tabular}{llll}
\hline$D$ est $/ F_{\text {ST }}$ & 1895 & 1915 & 1923 \\
\hline 1895 & - & 0.039 & 0.045 \\
1915 & 0.055 & - & 0.005 \\
1923 & 0.037 & -0.003 & - \\
\hline
\end{tabular}

differentiation, among the different time periods was 0.034 and this was not significantly different from zero (CI: $-0.047-0.113$, one sample $t$ test against $0, t=1.768$, d.f. $=6, P=$ $0.13)$.

\subsection{Inbreeding and presence of diploid males}

We detected high inbreeding coefficients $\left(F_{\text {IS }}\right)$ across all loci $(0.415 \pm 0.387$, mean \pm SD) (Table II). Both the years 1915 and 1923 were significantly different from zero (one sample $t$ test against 0, d.f. $=6, t=3.31, P=0.028$ and $t=$ 3.03, $P=0.038$, respectively). The inbreeding corrected for null alleles based on IIM ( $F_{\text {IS }}$ IIM) across all loci was much lower: $0.262 \pm 0.194$ (Table II), but was still significantly different from zero for each time period (one sample $t$ test against $0, d . f .=6, t=5.75, P=0.001$ for 1915; $t=4.86, P=0.003$ for 1923 ; and $t=5.81$, $P=0.001$ for 1895) (Table II). Significant inbreeding was supported by the occurrence of diploid males in each time period: one in 1895 $(n=10)$ and three in both the years $1915(n=20)$ and $1923(n=20)$.

\subsection{Test for bottleneck presence}

The calculated $M$ ratios averaged across loci, were 0.650 in $1895,0.673$ in 1915 , and 0.662 in 1923. Based on the generally accepted critical $M$ ratio of $M_{\mathrm{C}} \leq 0.680$ as described by Garza and Williamson (2001), the population of all three time periods showed evidence of a bottleneck. When comparing the calculated $M$ ratios averaged across loci with the here simulated $M_{\mathrm{C}}$ ratios, which ranged from 0.639 to 0.831 , each population showed also signs of having passed through a bottleneck except for combinations using extreme parameter values. The parameter settings of the calculation were $\Delta_{g}=3.5, \mu=$ 0.20 and $p_{s}=5$ and 10 , and the resulting $M_{\mathrm{C}}$ ratios were 0.639 and 0.643 , respectively. It should be noticed that for small data sizes, as is here the case for the year 1895, the interpretation of the results can be problematic because of stochastic effects (Garza and Williamson 2001); however, the generated data are valid for the other time periods.

\subsection{Simulation of $\mathbf{H}_{E}$ evolution in declining populations}

The simulations for different ancestral effective population sizes $\left(N_{\mathrm{Ae}}=100\right.$ to 15,000$)$ over 28 generations resulted in marginal losses of $H_{\mathrm{E}}$ of around or less than 0.05 even when starting with a strong negative growth factor of $5 \%$.

\section{DISCUSSION}

In this project, we used a set of eight microsatellites to genotype museum specimens of $B$. veteranus. Then, we analyzed how genetic parameters of bumblebee populations (i.e., allelic richness, observed and expected heterozygosities, genetic differentiation, and inbreeding) evolved over a period of three decades (1895-1923). In all the time periods, we detected low heterozygosities and positive inbreeding coefficients (the $F_{\text {IS }}$ values ranged from 0.383 to 0.441 ) which can be caused by several factors such as the presence of null alleles, population subdivision, and inbreeding (Callen et al. 1993). For null alleles, the program MicroChecker 2.2.3 confirmed the presence of null alleles in our data, but the frequencies were low in all loci. After we corrected for null alleles based on the individual inbreeding model IIM, the inbreeding coefficients stayed high ( $F_{\text {IS }}$ IIM ranging from 0.241 to 0.284 ) which is indicating that the high inbreeding coefficients cannot be explained by the occurrences of null alleles. Similarly, population subdivision can be excluded as a factor 
here for our data since the genetic differentiation observed in $B$. veteranus $\left(F_{\mathrm{ST}}=0.024\right)$ was small. In continuation of our analysis, it seemed to be more likely that the significant positive inbreeding coefficients have been influenced by high levels of inbreeding. Indeed the presence of inbreeding was confirmed by the occurrence of sterile diploid males in the three time periods. Our data demonstrated that the population of $B$. veteranus in Belgium showed inbreeding between 1915 and 1923, with the indication that this phenomenon was already present since 1895 . Thus inbreeding was already present $25-30$ years before the actual decline of $B$. veteranus that started in Belgium around 1950 (Rasmont and Mersch 1988; Rasmont et al. 1993). As a consequence, we believe that the data obtained therefore suggest that the observed inbreeding did not directly result in the collapse of $B$. veteranus.

As reported by Goulson et al. (2008), it is expected that populations of declining species become rare and isolated. As a consequence, populations of declining species exhibit a loss of genetic diversity (drop in heterozygosity and allelic richness) and gene flow over time, while for stable populations such changes are less likely to occur (Goulson et al. 2008). In this context, we ran a simulation of over 28 generations with $B$. veteranus. However, these simulations demonstrated that in most of the cases, a reduction in population size (simulating bumblebee decline) resulted in a marginal loss of $H_{\mathrm{E}}$ of around or less than 0.05 . Interestingly, our simulation data agree with those of Lozier and Cameron (2009) as these authors could also not detect a major drop in $H_{\mathrm{E}}$ in a simulation of over 38 generations in the declining bumblebee species Bombus pensylvanicus. So both simulations do not show a major drop in $H_{\mathrm{E}}$ over time. In their review, Goulson et al. (2008) presented the hypothesis that the genetic diversity $\left(N_{\mathrm{A}}\right.$ and $\left.H_{\mathrm{E}}\right)$ in current declined species is reduced as compared to other common Bombus species. But without actually knowing the ancestral $H_{\mathrm{E}}$, it is difficult to conclude if a drop of $H_{\mathrm{E}}$ really occurred. Indeed, our data are strong indicatives that $B$. veteranus already had a low $H_{\mathrm{E}}$ before its decline. This agrees with a low $H_{\mathrm{E}}$ in the old specimens of $B$. pensylvanicus that is a declined bumblebee species in the USA (Lozier and Cameron 2009).

As reported by Rasmont and Mersch (1988), Rasmont et al. (1993), and Goulson et al. (2008), general drivers like the reduction in floral resources by agricultural intensification acted around 1950 for bumblebee decline. With the data obtained in this project, we can postulate the hypothesis that bumblebees with a low genetic diversity were then the first to decline. Hence, they were less prepared to face these troubled times or less adapted to this new environment. Furthermore, the low $H_{\mathrm{E}}$ we found in all populations could also be explained by the fact that $B$. veteranus was a source-sink population in Belgium, as this species is well-known for its sudden appearance in different parts in Europe (Söderman 1999; Rasmont and Iserbyt 2010). Indeed in agreement with the low genetic diversity, each time period demonstrated signs of the occurrence of a genetic bottleneck. Here, the presence of a bottleneck is based on the $M$ values; however, we notice here that some $M$ values should be interpreted with some caution since they can be sensitive to outliers in small data sets. In addition to those general drivers affecting the bumblebee populations, Voveikov (1953) described that $B$. veteranus is often inquilines of other Thoracobombus species such as Bombus sylvarum, Bombus muscuorum, Bombus humilis, and Bombus ruderarius. This phenomenon of $B$. veteranus being dependent on the nesting behavior of other species, could have made this species even more vulnerable toward extinction. Our data showed that $B$. veteranus remained abundantly present in Belgium until the 1950 and this in spite of the high inbreeding coefficients and the low genetic diversity presented in the population. This is unexpected in the case that inbreeding would have had major effects on the species success. Nonetheless, no inbreeding depression was detected here. These results are similar to those of $B$. terrestris in Tasmania (Schmid-Hempel et al. 2007). The latter study demonstrated that despite a drastic genetic bottleneck, $B$. terrestris could successfully invade and colonize Tasmania. Therefore, we 
believe that this population was robust against the possible effects of a low genetic diversity and/or associated inbreeding. But it has also to be noted that in Tasmania, there was a very favorable environment with no direct inter-species competition and no pathogens. However, negative effects of inbreeding have been reported, like the production of diploid males. In the case this happens, then the queens who mate with diploid males are unable to initiate a colony and also diploid males do not work for the colony which will also have a negative effect on the population growth rate (Cook and Crozier 1995; Gerloff and Schmid-Hempel 2005; Whitehorn et al. 2009). Furthermore, our result of detecting inbreeding without inbreeding depression could be explained by the hypothesis that the haplodiploid sex determination system of Hymenoptera is leading to a strong effect of purging selection against recessive deleterious alleles in the haploid males (Sorati et al. 1996; Packer and Owen 2001).

In conclusion, our data with $B$. veteranus demonstrated inbreeding over a period of 1895 to 1923 while the population remained stable, implying that inbreeding does not directly trigger the actual decline and/or extinction of bumblebees. However, inbreeding might still play an indirect role in the decline of bumblebee populations because of the appearance of diploid males and because a low $H_{\mathrm{E}}$ might reduce the capacity of the bumblebee population to react on environmental changes.

\section{ACKNOWLEDGMENTS}

This project was supported by the Special Research Fund of Ghent University, the Fund for Scientific Research-Flanders (FWO-Vlaanderen), and the Fonds de la Recherche Scientifique-Fonds de la Recherche Fondamentale Collective (FNRSFRFC) (FRFC convention no. 2.4618.12).

Bombus veteranus : l'analyse de microsatellites de cette espèce à partir d'échantillons d'un museum révèle une consanguinité avant leur régression.

Microsatellites / ADN ancien / collections muséographiques / diversité génétique / déclin des bourdons
Mikrosatelliten-Analyse von Museumsproben verrät das Auftreten von Inzucht bereits vor dem Rückgang von Bombus veteranus.

Mikrosatelliten / ancient DNA / Museumssammlungen / geneRückgang von Hummeln / Rückgang von Hummeln

\section{REFERENCES}

Anderson, C.N.K., Ramakrishnan, U., Chan, Y.L., Hadly, E.A. (2005) Serial SimCoal: a population genetic model for data from multiple populations and points in time. Bioinformatics 21, 17331734

Ashley, M.V., Berger-Wolf, T.Y., Caballero, I.C., Chaovalitwongse, W., Dasgupta, B., et al. (2008) Full siblings reconstruction in wild populations from microsatellite genetic markers. Nova, Hauppauge. Computational Biology: New Research

Ashley, M.V., Caballero, I.C., Chaovalitwongse, W., Dasgupta, B., Govindan, P., Sheikh, S.I., BergerWolf, T.Y. (2009) KINALYZER, a computer program for reconstructing sibling groups. Mol. Ecol. Resour. 9, 1127-1131

Blacquière, T., Smagghe, G., Van Gestel, C.A.M., Mommaerts, V. (2012) Neonicotinoids in bees: a review on concentrations, side-effects and riskassessment. Ecotoxicoly 21, 973-992

Callen, D.F., Thompson, A.D., Shen, Y., Phillips, H.A., Richards, R.I., Mulley, J.C., Sutherland, G.R. (1993) Incidence and origin of "null" alleles in the (AC)n microsatellite markers. Am. J. Hum. Genet 52, 922-927

Cameron, S.A., Lozier, J.D., Strange, J.P., Koch, J.B., Cordes, N., Solter, L.F., Griswold, T.L. (2011) Patterns of widespread decline in North American bumble bees. Proc. Natl. Acad. Sci. USA 18, 662-667

Chapuis, M.-P., Estoup, A. (2007) Microsatellite null alleles and estimation of population differentiation. Mol. Biol. Evol 24, 621-631

Chapuis, M.-P., Lecoq, M., Michalakis, Y., Loiseau, A., Sword, G.A., Piry, S., Estoup, A. (2008) Do outbreaks affect genetic population structure? A worldwide survey in Locusta migratoria, a pest plagued by microsatellite null alleles. Mol. Ecol 17, 3640-3653

Chybicki, I.J., Burczyk, J. (2009) Simultaneous estimation of null alleles and inbreeding coefficients. J. Hered 100, 106-113

Connop, S., Hill, T., Steer, J., Shaw, P. (2010) The role of dietary breadth in national bumblebee (Bombus) declines: simple correlation? Biol. Conserv 143, 2739-2746 
Cook, J.M., Crozier, R.H. (1995) Sex determination and population biology in the Hymenoptera. Trends Ecol. Evol 10, 281-286

Crawford, N.G. (2010) SMOGD: software for the measurement of genetic diversity. Mol. Ecol. Resour 10, 556-557

Duchateau, M.J., Hishiba, H., Velthuis, H.H.W. (1994) Diploid males in the bumble bee Bombus terrestris. Entomol. Exp. Appl 71, 263-269

El Mousadik, A., Petit, R.J. (1996) Chloroplast DNA phylogeography of the argan tree of Morocco. Mol. Ecol 5, 547-555

Estoup, A., Solignac, M., Harry, M., Cornuet, J.-M. (1993) Characterization of (GT)n and (CT)n microsatellites in two insect species Apis mellifera and Bombus terrestris. Nucleic. Acid. Res 21, 1427-1431

Excoffier, L., Novembre, J., Schneider, S. (2000) SimCoal: a general coalescent program for simulation of molecular data in interconnected populations with arbitrary demography. J. Hered 91, 506-509

Frankham, R. (2005) Genetics and extinction. Biol. Conserv 126, 131-140

Garza, J.C., Williamson, E. (2001) Detection of reduction in population size using data from microsatellite DNA. Mol. Ecol 10, 305-318

Gerloff, C.U., Schmid-Hempel, P. (2005) Inbreeding depression and family variation in a social insect, Bombus terrestris (Hymenoptera: Apidae). Oikos 111, 67-80

Goudet, J. (2001) Fstat: a program to estimate and test gene diversities and fixation indices (version 2.9.3). Updated from Goudet, J. (1995): Fstat (version 1.2): a computer program to calculate F-statistics. J. Hered 86, 485-486

Goulson, D., Osborne, J.L. (2010) Foraging economics. Bumblebees: behaviour, ecology and conservation (ed. by D. Goulson), p. 96. Oxford University Press, Oxford, UK

Goulson, D., Lye, G.C., Darvill, B. (2008) Decline and conservation of bumble bees. Annu. Rev. Entomol 53, 191-208

Guinand, B., Scribner, K.T. (2003) Evaluation of methodology for detection of genetic bottlenecks: inferences from temporally replicated lake trout populations. C. R. Biol 326(Supplement 1), 61-67

Hines, H.M., Hendrix, S.D. (2005) Bumble bee (Hymenoptera: Apidae) diversity and abundance in tallgrass prairie patches: effects of local and landscape floral resources. Environ. Entomol. 34, 1477-1484

Jost, L. (2008) G(ST) and its relatives do not measure differentiation. Mol. Ecol. 17, 4015-4026

Keller, L.F., Waller, D.M. (2002) Inbreeding effects in wild populations. Trends Ecol. Evol. 17, 230-241
Klein, A.-M., Vaissière, B.E., Cane, J.H., SteffanDewenter, I., Cunningham, S.A., et al. (2007) Importance of pollinators in changing landscapes for world crops. Proc. R. Soc. B. 274, 303-313

Kremen, C., Williams, N.M., Aizen, M.A., GemmillHerren, B., Le Buhn, G., et al. (2007) Pollination and other ecosystem services produced by mobile organisms: a conceptual framework for the effects of land-use change. Ecol. Lett 10, 299-314

Lozier, J.D., Cameron, S.A. (2009) Comparative genetic analyses of historical and contemporary collections highlight contrasting demographic histories for the bumblebees Bombus pensylvanicus and B. impatiens in Illinois. Mol. Ecol 18, 1875-1886

Meeus, I., Brown, M.J.F., de Graaf, D.C., Smagghe, G. (2011) Effects of invasive parasites on bumble bee declines. Conserv. Biol 25, 662-671

Nei, M. (1978) Estimation of average heterozygosity and genetic distance from a small number of individuals. Genetics 89, 583-590

Packer, L., Owen, R. (2001) Population genetic aspects of pollinator decline. Conserv. Ecol 5, 4

Pauly, A., Rasmont, P. (2010) Les bourdons de la Belgique. Website Atlas Hymenoptera, Gembloux Agro-Biotech, Université de Mons, Gembloux, Mons. http://www.zoologie.umh.ac.be/hymenoptera/ page.asp?id=160. Accessed 10 January, 2012.

Peakall, R., Smouse, F. (2006) GENALEX 6: Genetic Analysis in Excel. Population Genetic Software for Teaching and Research. Australian National University, Canberra, Australia

Rasmont, P., Iserbyt, I. (2010) Atlas of the European Bees: genus Bombus. STEP Project, Atlas Hymenoptera, Mons, Gembloux. http:// www.zoologie.umh.ac.be//hymenoptera/page.asp? $\mathrm{ID}=169$. Accessed 25 December, 2011.

Rasmont, P., Mersch, P. (1988) Premiere estimation de la dérive faunique chez les bourdons de la Belgique (Hymenoptera, Apidae). Ann. Soc. Royal Zool. Bel 118, 141-147

Rasmont, P., Leclercq, J., Jacob-Remacle, A., Pauly, A., Gaspar, C. (1993) The faunistic drift of Apoidea in Belgium. pp. 65-87, in Bruneau, E., Bees for pollination, Commission of the European Communities, Brussels, $237 \mathrm{pp}$.

Rasmont, P., Pauly, A., Terzo, M., Patiny, S., Michez, D., Iserbyt, S., Barbier, Y., Haubruge, E. (2005) The survey of wild bees (Hymenoptera, Apoidea) in Belgium and France. FAO, Roma, 18 pp.

Reber Funk, C., Schmidt-Hempel, R., Schmid-Hempel, P. (2006) Microsatellite loci for Bombus spp. Mol. Ecol. Notes 6, 83-86

Schmid-Hempel, P., Schmid-Hempel, R., Brunner, P.C., Seeman, O.D., Allen, G.R. (2007) Invasion success of the bumblebee, Bombus terrestris, despite a drastic genetic bottleneck. Heredity 99, 414-422 
Söderman, G. (1999) Diversity of pollinator communities in Eastern Fennoskandia and Eastern Baltics. Results from pilot monitoring with yellow traps in 1997-1998. The Finnish Environment 355, Finnish Environment Institute, Helsinki.

Sorati, M., Newman, M., Hovman, A.A. (1996) Inbreeding and incompatibility in Trichogramma brassicae: evidence and implications for quality control. Entomol. Exp. Appl 78, 283-290

Strange, J.P., Knoblett, J., Griswold, T. (2009) DNA amplification from pin-mounted bumble bees (Bombus) in a museum collection: effects of fragment size and specimen age on successful PCR. Apidologie 40, 134-139

Stroot, P., Depiereux (1989) Proposition d'une méthodologie pour établir des listes rouges d'invertébrés menacé. Biol. Conserv 48, 163-179

Thompson, H.M. (2001) Assessing the exposure and toxicity of pesticides to bumblebees (Bombus sp.). Apidologie 32, 305-321
Van Oosterhout, C., Hutchinson, W.F., Wills, D.P.M., Shipley, P. (2004) MICROCHECKER: software for identifying and correcting genotyping errors. Mol. Ecol. Notes 4, 535-538

Voveikov, G.S. (1953) Estestvennaya smena samok vo cem'ya shchmelej (Hym. Bomb.). Russkoe entomol obozrenie 33, 174-184

Wandeler, P., Hoeck, P.E.A., Keller, L.F. (2007) Back to the future: museum specimens in population genetics. Trends Ecol. Evol 22, 634-642

Wang, J.L. (2004) Sibship reconstruction from genetic data with typing errors. Genetics 166, 1963-1979

Whitehorn, P.R., Tinsley, M.C., Brown, M.J.F., Darvill, B., Goulson, D. (2009) Impacts of inbreeding on bumblebee colony fitness under field conditions. BMC Evol. Biol 9, 152

Williams, P.H. (1982) The distribution and decline of British bumble bees (Bombus Latr.). J. Apic. Res 21, 236-245

Zayed, A. (2009) Bee genetics and conservation. Apidologie 40, 237-262 